\title{
EFFECT OF pH ON ELECTROLESS Ni-P COATING OF CONDUCTIVE AND NON-CONDUCTIVE MATERIALS
}

\section{Moniruzzaman and Subrata Roy}

\author{
Department of Materials and Metallurgical Engineering \\ Bangladesh University of Engineering and Technology, Dhaka-1000, Bangladesh \\ E-mail: mmoniruzzaman@mme.buet.ac.bd
}

\begin{abstract}
Electroless nickel-phosphorus (Ni-P) coating of carbon steel as well as a polypropylene substrate was conducted using sodium hypophosphite as a reducing agent in alkaline media. The influence of $\mathrm{pH}$ on coating appearances and the properties of the coatings for both steel and the polypropylene substrate were studied. A nickel-phosphorus coating of good appearance was obtained in the $\mathrm{pH}$ range between 5.5 and 12.5 on the carbon steel substrate and between 8.5 and 12 on the polypropylene substrate. The percentage of $\mathrm{Ni}$ content in the coating increased with increasing $\mathrm{pH}$ of the bath solution. A smooth, uniform microstructure was found in the coating deposited in relatively lower $\mathrm{pH}$ solutions compared to higher $\mathrm{pH}$ baths. The microhardness of the $\mathrm{Ni}-\mathrm{P}$ coating decreased with an increasing percentage Ni content in the deposit.
\end{abstract}

Key Words: Electroless coating; nickel-phosphorus; solution pH; conditioning.

\section{INTRODUCTION}

$\mathrm{Ni}-\mathrm{P}$ alloys have been extensively used in the chemical, aerospace, automobile and textile industries due to their excellent wear resistance, corrosion resistance, solderability, polishability, magnetic properties, etc. (Matsubara et al., 2002). Today, the deposition process of electroless coating and thin films plays an important role in microelectronics (Shacham-Diamond et al., 2003). The outstanding characteristics of electroless nickel (EN) coatings include their ability to be applied to a variety of substrate materials such as metals (conductive) and non-metallic (non-conductive) materials and their ability to the plate uniformly on geometrically intricate parts since no external current is applied to the component (Parker 1972; Khoperia et al., 1997; Gemmler et al., 1990); therefore, this process is called electroless. Thus, it differs from the conventional electroplating processes that depend on an external source of direct current in order to reduce nickel ions in the electrolyte to nickel metal on the substrate. The electroless bath typically comprises an aqueous solution of metal ions, complex agents, reducing agents and stabilisers, operating in specific metal ion concentration, temperature and $\mathrm{pH}$ ranges. The rate of deposition and the properties of the coating depend on a number of factors such as the type and concentrations of the reducing agent, stabiliser, $\mathrm{pH}$, temperature of the bath solution, etc. Considerable work has been carried out to characterise binary electroless $\mathrm{Ni}-\mathrm{P}$ alloy deposits on metals, while the system on non-metals has been studied to a much lesser extent (Khoperia et al., 1997). This paper makes an attempt to study electroless nickel-phosphorus (Ni-P) coating on a non-metal material and to make a comparison with the process on metal using sodium hypophosphite as a reducing agent in alkaline media. 
The study was performed by electroless plating of Ni-P on two substrates: mild steel and polypropylene sheets. The effects of various process parameters such as bath composition, $\mathrm{pH}$ and temperature on the coating appearance, composition, microhardness and morphology were studied.

\section{EXPERIMENTAL DETAILS}

Mild steel sheets as well as polypropylene sheets $50 \times 20 \times 1 \mathrm{~mm}$ in size were taken as conducting and non-conducting substrates, respectively. All of the substrates were cleaned first to remove unwanted rust, impurities, lubricants, etc. The mild steel substrate was cleaned by pickling and acid dipping. Conditioning, sensitisation and activation treatment was applied to polypropylene sheet for its cleaning and pretreatment. The surface cleaning solution, pretreatment solution and the operating conditions for mild steel and polypropylene sheets are given in Table 1 and Table 2, respectively.

An electroless plating setup was developed. This comprises a $50 \mathrm{~mL}$ beaker, a thermometer holder, a perspex holder, a hot plate, a thermometer and a holder. The beaker contained the plating solution and was placed on the hot plate. The holder held the thermometer to measure the solution temperature. At first, two thirds of the beaker were filled with the plating solution, and then heated to a specific temperature. The plating test was done at $70^{\circ} \mathrm{C}$. The pretreated substrate was immersed into the plating solution held with the perspex holder. Then, deposition continued for one hour for the mild steel substrate. These depositions were done at different $\mathrm{pH}$ levels of the plating bath, including $\mathrm{pH} 5.5,6.5,7.5,8.5,9.5$ and 10.5, consecutively, up to $\mathrm{pH} 13$. For the polypropylene substrate, the bath $\mathrm{pH}$ values were $\mathrm{pH} 5,6,8.5,10,11.7,12$ and 12.4 and the deposition process continued for 10 to 20 minutes. Two depositions on the polypropylene substrate were also conducted at $50^{\circ} \mathrm{C}$. The plating bath composition for both mild steel and polypropylene sheets is shown in Table 3.

Table 1. Solution and operating conditions employed for cleaning the mild steel sheet

\begin{tabular}{ccc}
\hline Treatment type & HCl, \% & Temperature, ${ }^{\mathbf{0}} \mathbf{C}$ \\
\hline Pickling & 10 & 70 \\
Dipping & 30 & Room \\
\hline
\end{tabular}

Table 2. Solution and operating conditions employed for pretreatment of polypropylene sheets

\begin{tabular}{lccc}
\hline Treatment type Concentration & Temperature & Time (min) \\
\hline \multirow{3}{*}{ Conditioning } & $\mathrm{H}_{2} \mathrm{SO}_{4}: 100 \mathrm{~mL} / \mathrm{L}$ & & \\
& $\mathrm{K}_{2} \mathrm{Cr}_{2} \mathrm{O}_{7}: 15 \mathrm{~g} / \mathrm{L}$ & $65^{\circ} \mathrm{C}$ & 10 \\
\multirow{2}{*}{ Sensitising } & $\mathrm{H}_{2} \mathrm{O}: 30 \mathrm{~g} / \mathrm{L}$ & & \\
& $\mathrm{SnCl}_{2}: 10 \mathrm{~g} / \mathrm{L}$ & Room & 3 \\
\multirow{2}{*}{ Activating } & $\mathrm{HCl}^{*}: 40 \mathrm{~g} / \mathrm{L}$ & & \\
& $\mathrm{PdCl}_{2}: 0.1 \mathrm{~g} / \mathrm{L}$ & Room & $3-5$ \\
\hline
\end{tabular}


Table 3. Plating bath solution for steel and polypropylene sheets

\begin{tabular}{lc}
\hline Compounds & Concentration (g/L) \\
\hline $\mathrm{NiCl}_{2}, 6 \mathrm{H}_{2} \mathrm{O}$ & 30 \\
$\mathrm{NaH}_{2} \mathrm{PO}_{2}$ & 10 \\
$\mathrm{NaOH}$ & A few drops (to maintain the desired $\mathrm{pH}$ ) \\
\hline
\end{tabular}

The coating appearance was observed carefully just after deposition by the naked eye. After deposition, the sample was washed with distilled water and dried with acetone. Conventional wet chemical analysis methods were used to measure the percentage of $\mathrm{Ni}$ on the deposit surface. Hardness measurements were taken using a Shimadzu Vickers Microhardness Tester (Micromet II) with a diamond indenter. The chosen load was $50 \mathrm{~g}$ for 10 seconds. Special care was taken so that, in all cases, the depth of the indentation was less than one-fifth of the coating thickness in order to eliminate the substrate effect. The values reported represent the average of at least five microhardness readings. A XL30 Philips scanning electron microscope (SEM) was employed to inspect the surface morphology of the coatings.

\section{RESULTS AND DISCUSSION}

\section{Effect of pH on Appearances of Electroless Ni-P Coating}

Electroless plating on the mild steel substrate was done in bath solutions with different $\mathrm{pH}$ values at a fixed temperature of $70^{\circ} \mathrm{C}$ for a period of 1 hour. The results in terms of coating appearance at different $\mathrm{pH}$ values of the bath solution are given in Table 4 . The surface showed scattered a thin coating at $\mathrm{pH}$ levels of 5.5 and 12.5. Coatings with variable appearances (good, fair, very good) were obtained from bath solutions having $\mathrm{pH}$ values in between, and the best appearance was found in the coating deposited from the bath solution with a $\mathrm{pH}$ of 7.5. No significant coatings were obtained from the bath solutions at $\mathrm{pH} 5.5$ or lower and at $\mathrm{pH}$ values of 12.5 or higher. Thus, electroless Ni-P coatings can be obtained from the given bath composition in the $\mathrm{pH}$ range between 5.5 and 12.5. Two distinct coating appearances are shown in Figure 1.

Table 4. Appearances of Ni-P coatings on the mild steel substrate at different $\mathrm{pH}$ levels

\begin{tabular}{cl}
\hline Bath pH & Coating appearance \\
\hline 5.5 & Scattered thin coating \\
6.5 & Fair \\
7.5 & Very good \\
8.5 & Good \\
9.5 & Good \\
10.5 & Fair \\
11.5 & Good \\
12.5 & Scattered thin coating \\
13.0 & Very scattered thin coating \\
\hline
\end{tabular}




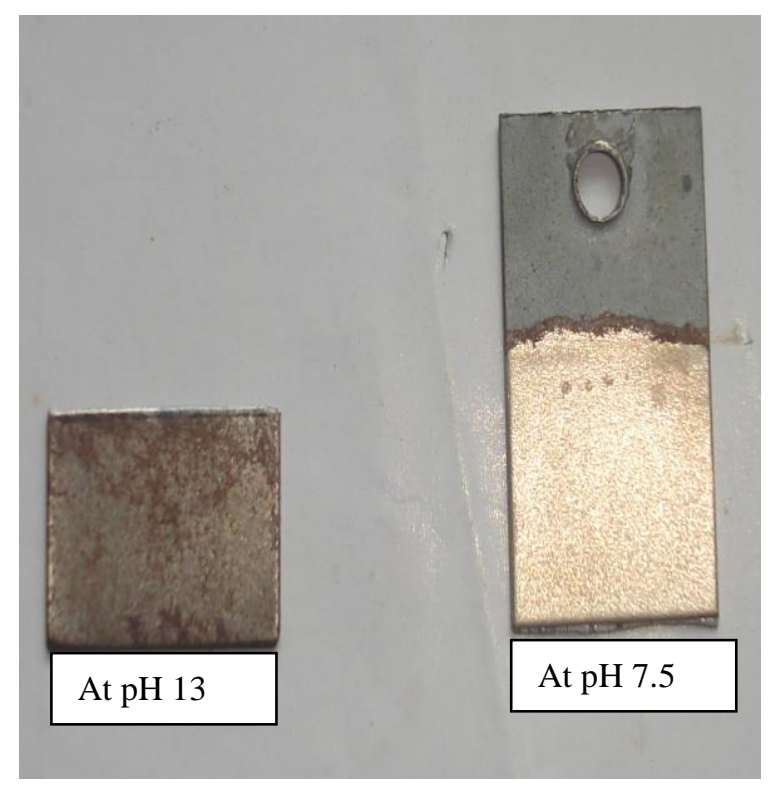

Figure 1. Comparison of the surface appearance of the Ni-P deposit on the mild steel substrate at $\mathrm{pH} 7.5$ and 13

Coating or plating on the polypropylene substrate was rather difficult. The coating appearance as a function of bath $\mathrm{pH}$, temperature and time are summarised in Table 5. Variation of only the bath $\mathrm{pH}$ could not produce good coatings. The temperature and time were also varied in order to get coatings with a pleasing appearance. Bright deposition was obtained only under three conditions. No deposition was found at $\mathrm{pH}$ values of 12 or higher. Deposition was not seen with a bath $\mathrm{pH}$ of 12.4 if the temperature and time were changed to $50^{\circ} \mathrm{C}$ and 10 minutes, respectively. Brighter coatings were obtained from baths within a relatively narrow $\mathrm{pH}$ range between 8.5 and 12. A comparison of the bright and dark coating appearances on the polypropylene substrate is shown in Figure 2.

Table 5. Appearance of Ni-P coatings on the polypropylene substrate at different bath $\mathrm{pH}$ levels, times and temperatures

\begin{tabular}{cccl}
\hline $\begin{array}{c}\text { Temperature } \\
\left({ }^{\mathbf{O}} \mathbf{C}\right)\end{array}$ & $\begin{array}{c}\text { Time } \\
(\mathbf{m i n})\end{array}$ & Bath pH & \multicolumn{1}{c}{ Coating appearance } \\
\hline 70 & 10 & 5 & darker deposition \\
50 & 10 & 6 & darker deposition \\
70 & 20 & 8.5 & slightly bright deposition \\
70 & 20 & 10 & brighter deposition \\
70 & 20 & 11.7 & brighter deposition \\
70 & 20 & 12 & no deposition \\
50 & 10 & 12.4 & no deposition \\
\hline
\end{tabular}




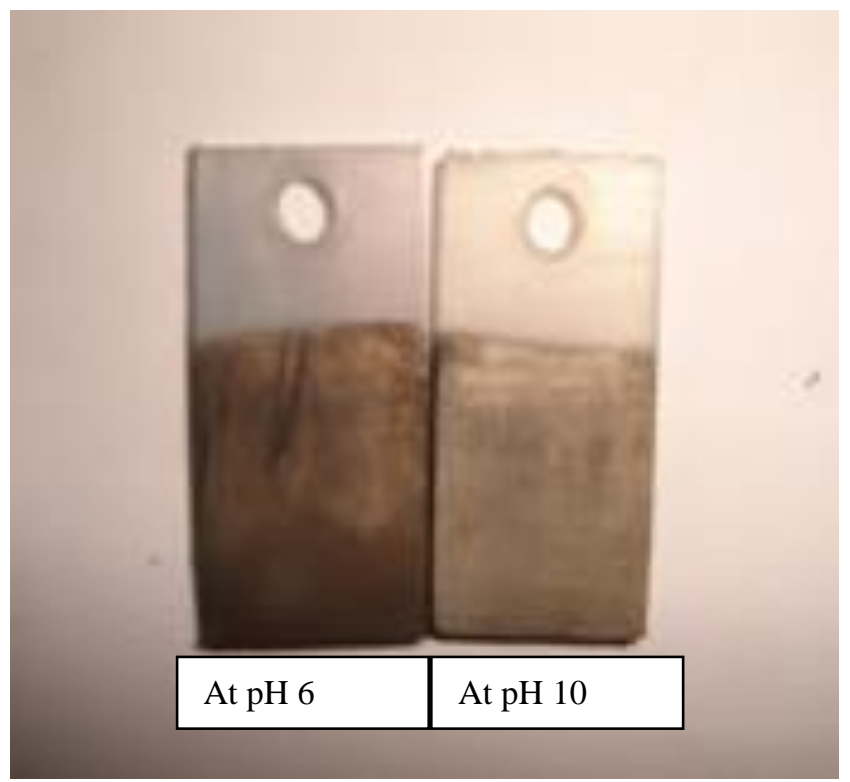

Figure 2. Comparison of the surface appearance of Ni-P coatings on the polypropylene substrate at $\mathrm{pH} 10$ and 6.

From Figures 1 and 2, it can be seen that the criteria for electroless deposition of $\mathrm{Ni}-\mathrm{P}$ on steel and polypropylene materials were not exactly the same. Good deposition could be obtained from the chloride bath within the $\mathrm{pH}$ range from 5.5 to 12.5 . The $\mathrm{pH}$ range was relatively narrow $(12>\mathrm{pH}>8.5)$ for good deposition of Ni-P on the polypropylene material from the chloride bath of the same chemical composition. The reason for different $\mathrm{pH}$ ranges for good deposition on the steel and polypropylene substrates might be attributed to the fact that higher $\mathrm{pH}$ values change the surface charge on the substrate, which affects the deposition phenomenon (Gou et al., 2010).

\section{Chemical Analysis of Ni-P Coatings}

The percentages of $\mathrm{Ni}$ in the coatings with respect to the bath $\mathrm{pH}$ were determined and are presented in Figure 3. For a bath with $\mathrm{pH} 7.5$, the percentage of $\mathrm{Ni}$ in the deposits was found to be $62.86 \%$. It can be seen that an increase in the percentage of Ni content in the deposit with an increase in the $\mathrm{pH}$ value of the bath solution on the mild steel substrate was linear. Doong and Duh (1995) also reported that the percentage of Ni increases with an increase in bath $\mathrm{pH}$ value during electroless Ni plating on mild steel. A similar trend of increasing Ni content in the coatings with an increase in bath $\mathrm{pH}$ was also observed for electroless nickel deposition on the polypropylene sheet. The increasing nickel content in the coatings with an increasing bath $\mathrm{pH}$ means that the phosphorus content in coating decreased with increasing $\mathrm{pH}$ of the bath solution. $\mathrm{NaH}_{2} \mathrm{PO}_{2}$ is used in the bath as the reductant. Hypophosphite ions $\left(\mathrm{H}_{2} \mathrm{PO}_{2}{ }^{-}\right)$have a redoxic potential of $-0.5 \mathrm{~V}$ and nickel ions have a potential of $-0.25 \mathrm{~V}$ (Fontana, 2005). The reactions for the deposition of $\mathrm{Ni}$ and $\mathrm{P}$ are presented in Eq. (1) to Eq. (3):

$$
\begin{aligned}
& \mathrm{H}_{2} \mathrm{PO}_{2}^{-}+\mathrm{H}_{2} \mathrm{O} \longrightarrow \mathrm{H}^{+}+\mathrm{HPO}_{3}^{-2}+2 \mathrm{H} \\
& \mathrm{Ni}^{2+}+2 \mathrm{H} \longrightarrow \mathrm{Ni}+2 \mathrm{H}^{+} \\
& \mathrm{H}_{2} \mathrm{PO}_{2}{ }^{-}+\mathrm{H} \longrightarrow \mathrm{P}+\mathrm{OH}^{-}+\mathrm{H}_{2} \mathrm{O}
\end{aligned}
$$




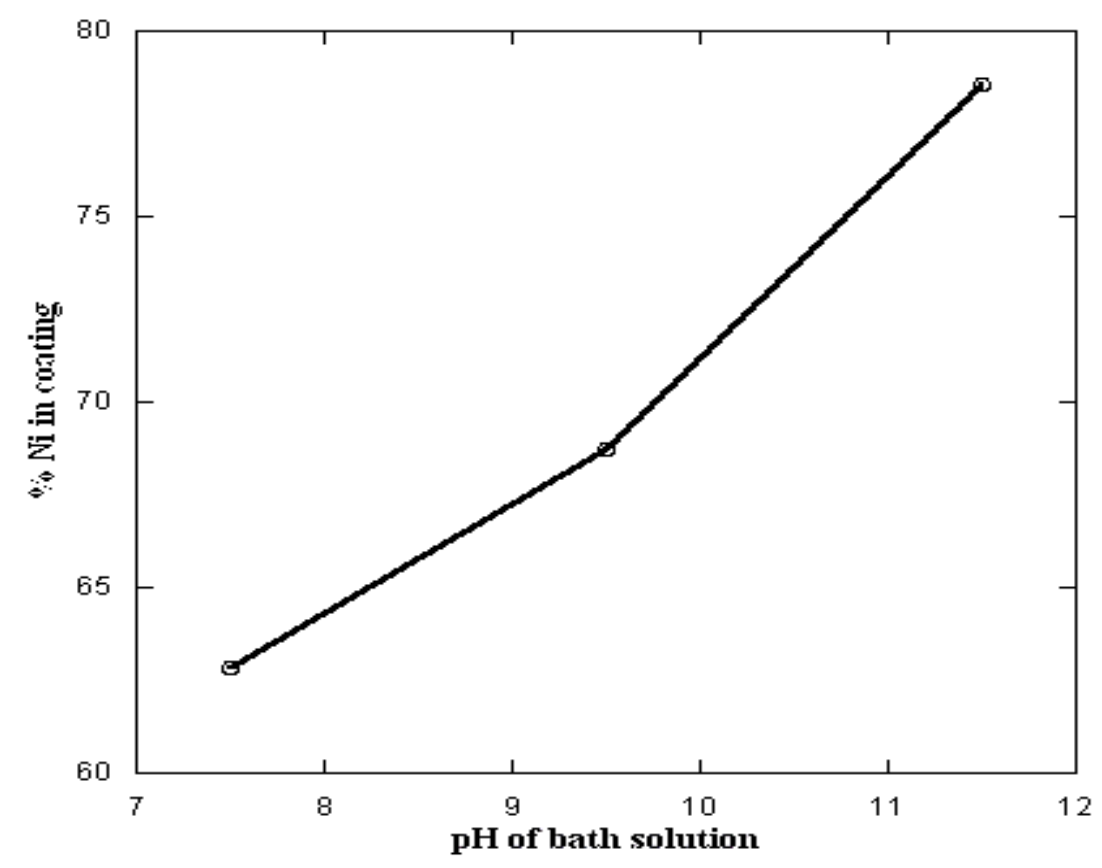

Figure 3. The percentage of $\mathrm{Ni}$ on the coated surface as a function of the $\mathrm{pH}$ of the bath solution

It can be seen from reaction (2) that the greater the concentration of $\mathrm{H}^{+}$in the bath solution, the less the deposition of $\mathrm{Ni}$ is favoured. At low $\mathrm{pH}$ values, the $\mathrm{H}^{+}$ concentration is high and the percentage of $\mathrm{Ni}$ content in the coating is low. As the $\mathrm{pH}$ value of the bath is raised, the reaction is shifted to the right of reaction (2); the $\mathrm{H}^{+}$ decreases and the percentage of $\mathrm{Ni}$ in the coating increases. After the $\mathrm{pH}$ reaches a certain value, i.e. 12.5 for mild steel and 12 for the polypropylene substrate, the bath solution becomes strongly alkaline and two factors appear. One is that the concentration of free $\mathrm{Ni}^{2+}$ becomes low (Haowen and Bangwie, 2002), and the other is that the resulting precipitation of basic salts in the bath consumes some $\mathrm{Ni}^{2+}$. Both of these actions finally stop deposition.

\section{Morphology of the Electroless Ni-P Coatings}

The morphology of different coatings deposited from the bath solution at different $\mathrm{pH}$ levels was investigated. The morphology was assessed by scanning electron microscopy (SEM). The SEM images of the deposits obtained at different $\mathrm{pH}$ levels of the bath solution are shown in Figure 4 for the mild steel substrate and in Figure 5 for the polypropylene substrate. The greatest uniformity in the microstructure was found in the coating obtained at $\mathrm{pH} 6.5$ [Figure 4(a)]. The non-uniformity of the surface was due to the different the percentage of $\mathrm{Ni}$ in the coating. The uniformity decreased with increasing bath $\mathrm{pH}$ [as shown in Figures 4(b) and (c)]. This means that uniformity in the microstructure decreased with increasing nickel content in the coating, i.e. with decreasing phosphorus content in the coating. The appearance of the surface layer of $\mathrm{Ni}-\mathrm{P}$ coatings differ depending on the amount of phosphorous in the coating and the deposition process conditions. With a low phosphorous content, the coating grains were separated by up to $20 \mathrm{~nm}$ deep gaps. Coatings with a high phosphorous content showed a more homogenous structure with only 3-8 nm deep gaps (Martyak et al., 1993). 

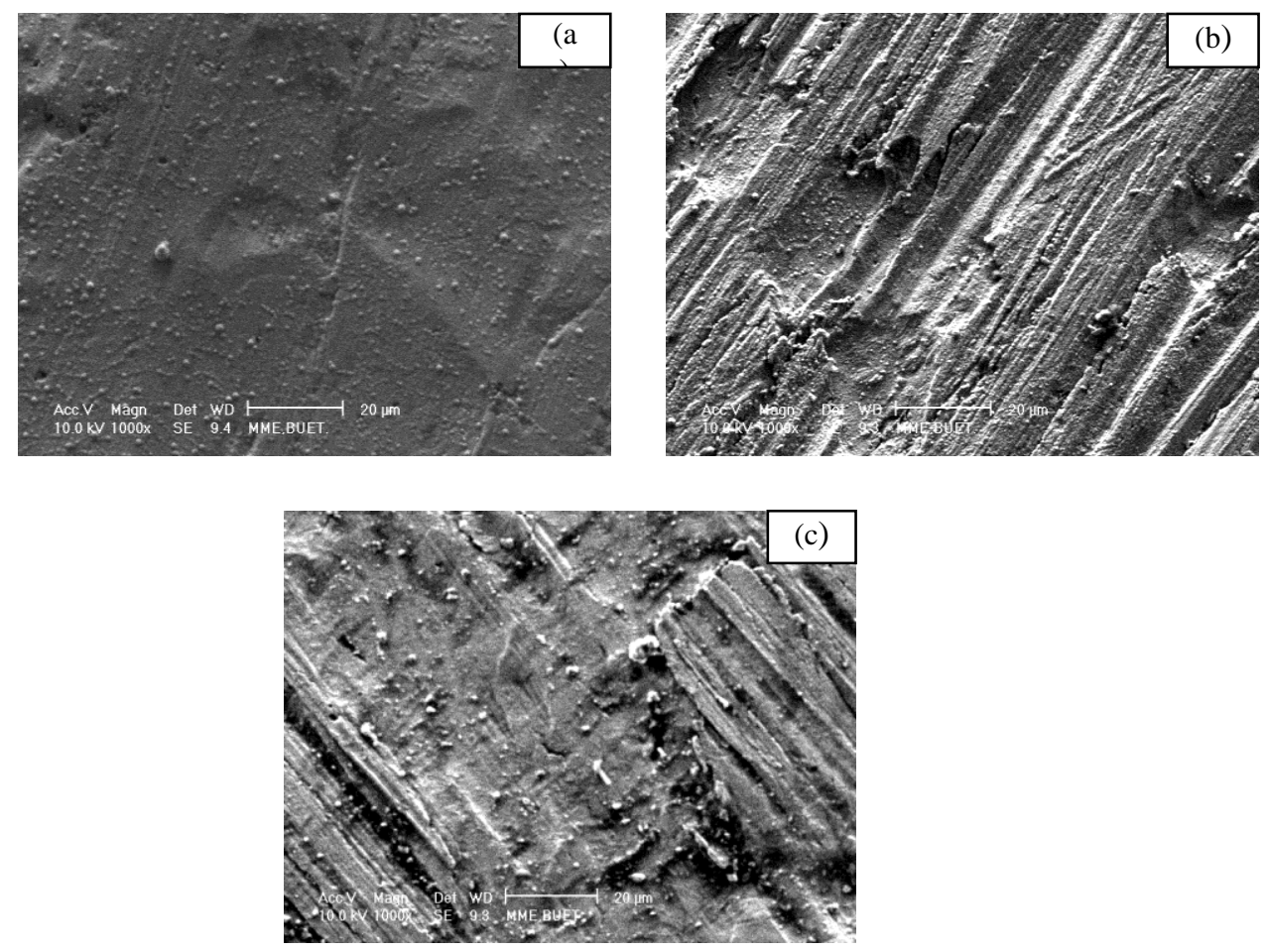

Figure 4. SEM image of electroless nickel coating deposited on the mild steel substrate from bath solutions having a $\mathrm{pH}$ value of (a) 6.5, (b) 8.5 and (c) 10.5
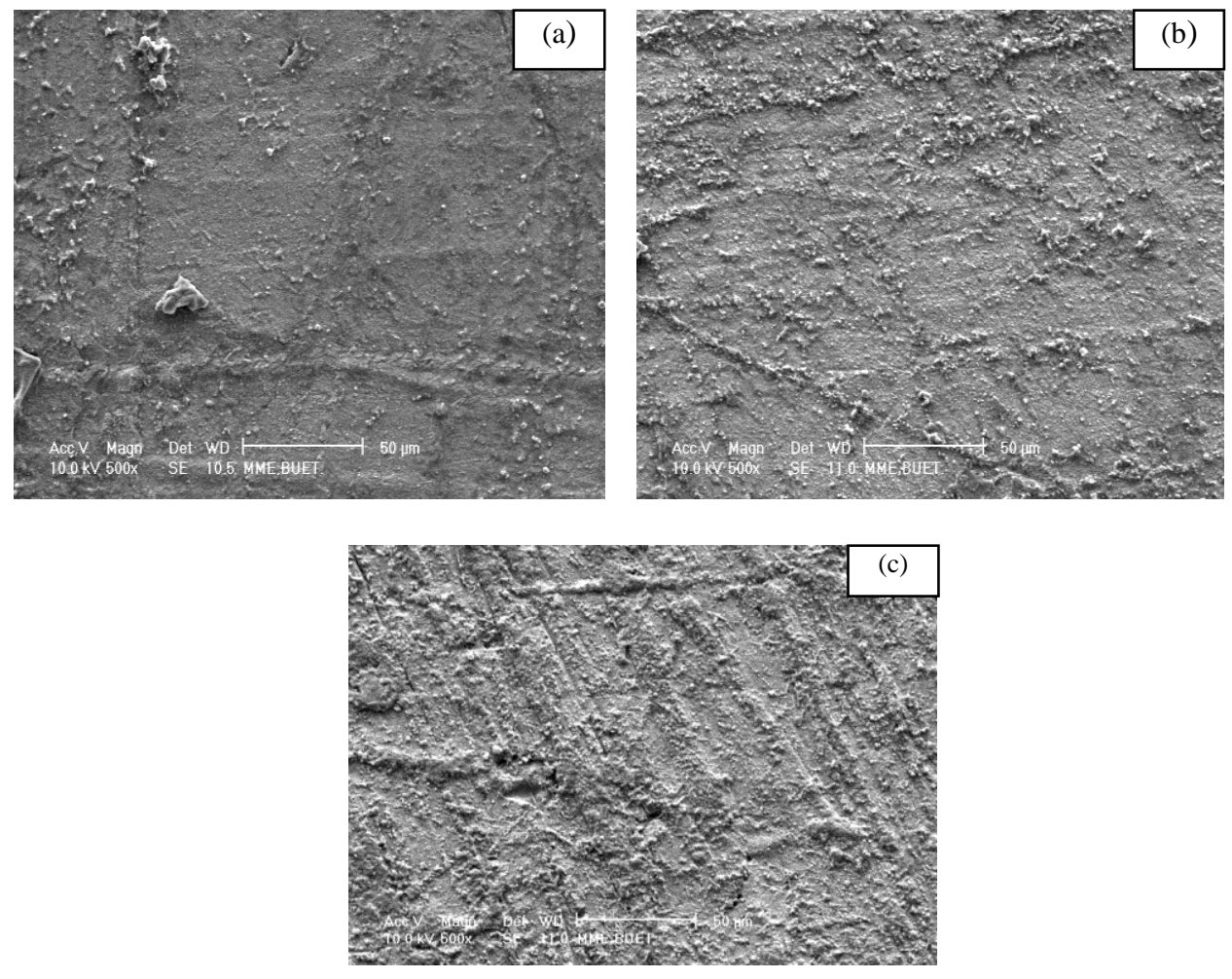

Figure 5. SEM image of Ni-P coatings deposited on the polypropylene substrate from bath solutions having a $\mathrm{pH}$ value of (a) 8.5, (b) 10 and (c) 11.7 
Thus, a relatively smooth microstructure was obtained in the coating containing a relatively higher phosphorus content (i.e. a lower nickel content) that was deposited from the bath with the low $\mathrm{pH}$ value of 6.5 . With a higher phosphorous content, improved smoothness or uniformity of the coatings was observed in the coatings for the polypropylene material, as can be seen in Figure 5. Here, the coating in Figure 5(a) deposited from bath with a $\mathrm{pH}$ of 8.5 had a higher phosphorus content and showed a smoother surface than the other coatings [Figure 5(b) and (c)].

\section{Microhardness of Electroless Ni-P Deposits}

All coatings on the mild steel substrate obtained at different $\mathrm{pH}$ values were tested for microhardness. From these microhardness tests on steel, it was found that the highest microhardness was found with $62.86 \% \mathrm{Ni}$ in the coating surface with a value of 196 VHN. However, microhardness values of $113 \mathrm{VHN}$ and $104 \mathrm{VHN}$ were found for $68.75 \%$ and $78.58 \% \mathrm{Ni}$ in the coatings, respectively. So, from these investigations, it can be said that the microhardness decreased as the percentage of $\mathrm{Ni}$ is increased. Figure 6 shows the variation in microhardness according to the percentage of $\mathrm{Ni}$ in the deposits.

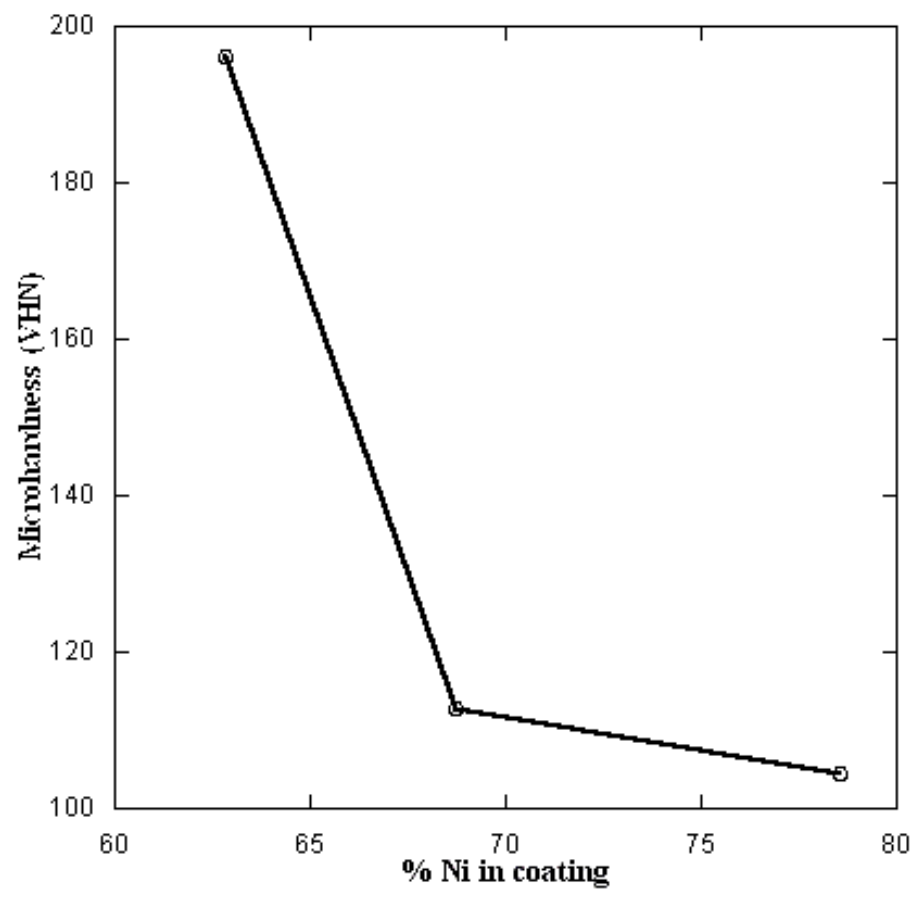

Figure 6. Variation of microhardness of Ni-P coatings according to the $\% \mathrm{Ni}$ content on the steel substrate

\section{CONCLUSION}

Electroless nickel coating on steel and polypropylene materials was conducted in this study. The effect of bath $\mathrm{pH}$ on the substrates, coating composition, microhardness and morphology was assessed. Based on the experimental results and analysis, the following conclusions have been drawn: 
1. The criteria for electroless deposition of Ni-P on steel and polypropylene materials are not identical. Electroless Ni-P coatings can be deposited on carbon steel substrates from a chloride bath solution in the $\mathrm{pH}$ range between 5.5 and 12.5 at $70^{\circ} \mathrm{C}$, whereas on polypropylene substrates, electroless deposition of Ni$\mathrm{P}$ from the same bath solution requires a $\mathrm{pH}$ range between 8.5 and 12 at $70^{\circ} \mathrm{C}$.

2. Ni-P coating of the best appearance on steel substrate was obtained at a $\mathrm{pH}$ of 7.5 and that on polypropylene substrate was obtained at a $\mathrm{pH}$ of 11.7.

3. The percentage Ni on the coating surface for both the steel and polypropylene substrates increased with an increase in the $\mathrm{pH}$ value of the bath solution.

4. Uniform and smooth microstructures were obtained at lower $\mathrm{pH}$ levels.

\section{REFERENCES}

Doong, J.C. and Duh, J.G. 1993. Effects of pH values in electroless Ni plating on mild steel with TiN coatings. Surface and Coatings Technology, 58(1): 19-28.

Fontana, M.G. 2005. Corrosion engineering. Tata McGraw-Hill Edition, p.42.

Gemmler, A., Zbolch, T., Gut, H. and Keller, W. 1990. Mechanism of electroless nickel deposition and its utilization in expert systems. Proceedings of the $77^{\text {th }}$ AESF Annual Technology Conference, Boston, MA, pp.595-608.

Gou, Y.N., Huang, W.J., Zeng, R.C. and Zhu, Y. 2010. Influence of pH values on electroless Ni-P-SiC plating on AZ91D magnesium alloy. Transactions of Nonferrous Metals Society of China, 20(2): S674-S678.

Haowen, X. and Bangwie, Z. 2002. Effects of preparation technology on the structure and amorphous forming region for electroless Ni-P alloys. Journal of Materials Processing Technology, 124(1-2): 8-13.

Khoperia, T.N., Tabatadze, T.J. and Zedgenidze, T.I. 1997. Formation of microcircuits in microelectronics by electroless deposition. Electrochimica Acta, 42: 30493055.

Martyak, N.M., Wetterer, S., Harrison, L., McNeil, M., Heu, R. and Neiderer, A.A. 1993. Stucture of electroless nickel coatings. Plating and Surface Finishing, 80(6): 60-64.

Matsubara, H., Yonekawa, T., Ishino, Y., Nishiyama, H., Saito, N. and Inoue, Y. 2002. Observation of initial deposition process of electroless nickel plating by quartz crystal microbalance method and microscopy. Electrochimica Acta, 47: 40114018.

Parker, K. 1972. Recent advances in electroless nickel deposits. $8^{\text {th }}$ International Conference, Forster-Verlag, Zurich, Switzerland, pp. 202-207.

Shacham-Diamond, Y., Inberg, A., Sverdlov, Y., Bogush, V., Croitoru, N., Moscovich, H. and Freeman, A. 2003. Electroless processes for micro- and nanoelectronics. Electrochimica Acta, 48: 2987-2996. 